\title{
Speciation of Aluminium in Human Serum Investigated by HPLC/High Resolution Inductively Coupled Plasma Mass Spectrometry (HR-ICP-MS): Effects of Sialic Acid Residues of the Carbohydrate Chain on the Binding Affinity of Aluminium for Transferrin
}

\author{
Megumi Hamano Nagaoka* and Tamio Maitani ${ }^{1}$ \\ National Institute of Health Sciences, 1-18-1 Kamiyoga, Setagaya-ku, Tokyo 158-8501, Japan
}

(Received October 27, 2008)

\begin{abstract}
Aluminium (Al) in the blood is bound to transferrin (Tf), a glycoprotein of about $80 \mathrm{kDa}$ that is characterized by its need for a synergistic anion. The binding affinity of both $\mathrm{Al}$ and iron $(\mathrm{Fe})$ for $\mathrm{Tf}$ is surveyed in the context of our recent studies by on-line high-performance liquid chromatography/high-resolution inductively coupled plasma mass spectrometry (HPLC/HR-ICP-MS). First, $\mathrm{Al}$ in human serum without any in vitro $\mathrm{Al}$-spikes was present in a form bound to the N-lobe site of human serum Tf (hTf). Next, the effects of sialic acid in the carbohydrate chain of hTf on the binding affinity of $\mathrm{Al}$ (or Fe) for hTf were studied by using asialo-hTf obtained by treating hTf with sialidase. The binding affinity of Fe for asialo-hTf and native-hTf was similar, but the binding affinity of Al for asialo-hTf was greater than that for native-hTf. These findings are discussed in relation to diseases in which the serum concentrations of carbohydrate-deficient $\mathrm{Tf}$ and oxalate are increased.
\end{abstract}

Key words_ _ speciation, aluminium, inductively coupled plasma mass spectrometry, transferrin, sialic acid, oxalate

\section{INTRODUCTION}

Aluminium (Al) is a component of soil, especially clay soils, and it is present in water. Al used to be considered non-toxic. However, the previously accepted view that $\mathrm{Al}$ is non-toxic is being questioned. Because $\mathrm{Al}$ was concluded to have a potential effect on the reproductive and developing nervous system at doses lower than those used in establishing the previous provisional tolerable weekly intake (PTWI, $7 \mathrm{mg} \mathrm{Al} / \mathrm{kg}$ body weight per week), the sixty-seventh meeting of the Joint Food and Agriculture Organization of the United $\mathrm{Na}-$ tions (FAO)/World Health Organization (WHO) Expert Committee on Food Additives (JECFA, 2006) withdrew the previous PTWI for $\mathrm{Al}$ and proposed

\footnotetext{
${ }^{1}$ Present address: University of Shizuoka, 52-1 Yada, Surugaku, Shizuoka 422-8526, Japan

*To whom correspondence should be addressed: National Institute of Health Sciences, 1-18-1 Kamiyoga, Setagaya-ku, Tokyo 158-8501, Japan. Tel.: +81-3-3700-9359; Fax: +813-3700-9359; E-mail: nagaoka@nihs.go.jp
}

a lower PTWI of $1 \mathrm{mg} / \mathrm{kg}$ body weight per week. ${ }^{1)}$ The Committee noted that the PTWI is likely to be greatly exceeded by some population groups, particularly children. Al has also been recognized as potentially neurotoxic for humans and animals, and it has been shown to inhibit the acetylcholinesterase activity in the brain ${ }^{2)}$ and to cause increased free radical effects. ${ }^{3)}$

$\mathrm{Al}$ in human blood is bound to transferrin (Tf) and transferred to receptors. Tfs are a group of iron $(\mathrm{Fe})$-binding glycoproteins that require carbonate anions for metal binding, ${ }^{4)}$ and they have two metal-binding sites: the N-lobe site and the Clobe site..$^{5-7)}$ The lobes are homologous but distinct, ${ }^{8)}$ and a striking difference between them is the presence of carbohydrate chain with sialic acid residues in the C-lobe. The carbohydrate chain can differ in its degree of branching and the differences are referred to microheterogeneity. ${ }^{9,10)}$ Carbohydrate-deficient Tfs (CDTs) have fewer sialic acid residues, and CDT levels are elevated in several diseases. ${ }^{11-16)}$ It is unclear whether the an- 
ionic charge on sialic acid in the C-lobe affects the binding affinity of metals for the N-lobe site and the C-lobe site.

Many studies have examined the binding of $\mathrm{Al}$ to human serum $\mathrm{Tf}$ (hTf) from a thermodynamic standpoint. ${ }^{17,18)} \mathrm{Al}$ forms stable complexes with citrate, and even more stable complexes with hTf. ${ }^{19)}$ Therefore, hTf is the predominant Al carrier in serum and passes through the blood-brain barrier. ${ }^{20)}$ To understand the mechanism of $\mathrm{Al}$ transport and $\mathrm{Al}$ accumulation, elucidation of the interactions between $\mathrm{Al}$ and hTf and the physiological factors that affect the interactions is essential.

This review surveys research on the binding affinity of $\mathrm{Al}$ for hTf in the context of our recent studies.

\section{CHEMICAL FORMS OF METALS BOUND TO hTf}

Hyphenated techniques have been used to speciate the chemical forms of $\mathrm{Al}$ in human blood in order to clarify the binding of Al to hTf. But few studies have been reported on the binding states of $\mathrm{Al}$ to hTf without any in vitro Al-spikes. Most studies have been conducted on Al-spiked serum ${ }^{21-23)}$ or serum from patients on continuous ambulatory peritoneal dialysis. ${ }^{24,25)}$ High-performance liquid chromatography/high-resolution inductively coupled plasma mass spectrometry (HPLC/HR-ICPMS) is one such hyphenated technique, and it combines HPLC as a separation method with HR-ICPMS as a metal detection method. ${ }^{26)}$ If the chemical forms of hTf can be separated into four chemical forms (for example, apo-, two monoferric and diferric hTfs), and if their Fe-content can be directly quantified, the preferential Fe-binding lobe and the need for synergistic anions can be clarified. In order to do so, we investigated the analytical method for metal ( $\mathrm{Fe}$ and $\mathrm{Al}$ ) binding to hTf with an HPLC instrument connected directly to an HR-ICP-MS instrument. ${ }^{27)}$

The operating conditions for the hyphenated HPLC and HR-ICP-MS system have been reported previously. ${ }^{27)}$ Briefly, an HPLC apparatus (LC10Ai; Shimadzu, Kyoto, Japan) equipped with an anion-exchange column (Mono-Q; Bio Sciences, Uppsala, Sweden) was connected directly to an ELEMENT 1 HR-ICP-MS instrument (Finnigan MAT, Bremen, Germany). A 0.1-ml sample was injected into the system, and the eluate was transferred to a UV detector and then introduced to the nebulizer of the HR-ICP-MS instrument. The levels of sulfur (S), $\mathrm{Al}$ and $\mathrm{Fe}$ were continuously monitored, and the ${ }^{32} \mathrm{~S}$ level was used to monitor the protein levels in the HPLC eluate.

New gradient conditions were established to separate all four chemical forms of the metals bound to hTf. Other gradient condition was established to analyze asialo-hTf solutions, because asialohTf contains a sialic acid-free sugar chain and behaves differently in anion-exchange experiments. ${ }^{28)}$ A thorough clean-up procedure was necessary to obtain a detection limit of $0.1 \mu \mathrm{g} / \mathrm{l}(\mathrm{S} / \mathrm{N}=3)$ for $\mathrm{Al}$ speciation. ${ }^{29)}$

As an assignment of four chemical forms, typical chromatograms obtained by HPLC/HR-ICP-MS are shown in Fig. 1. Four UV-peaks were detected [Fig. 1(A), upper panel], and three ${ }^{56} \mathrm{Fe}$-peaks were observed [Fig. 1(A), lower panel]. Iron in the form of iron citrate was added to the hTf solution. Since peak c did not show an Fe peak, it was assigned to apo-hTf. The ratios of ${ }^{56} \mathrm{Fe}$-peak areas to UV-peak areas were compared. The peaks a and $\mathrm{d}$ had almost same ratio of 1 . The peak $b$ had 1.8 -fold higher ratio than the peaks a and $d$. The peak $b$ was therefore assigned to $\mathrm{Fe}_{2}$-hTf (two $\mathrm{Fe}$ atoms bound to hTf). The peaks a and d were ascribed to monoferric hTfs, and DFO (desferrioxamine, desferal) was used to assign the two monoferric hTfs. DFO is a chelating agent that has been reported to preferentially remove $\mathrm{Fe}$ from the C-lobe site in hTf. ${ }^{30)} \mathrm{An}$ appropriate amount of DFO (DFO: hTf ratio $1: 4$ ) was added to the diferric hTf solution. In the absence of DFO, the principal peak of $\mathrm{Fe}_{2}$-hTf was detected [Fig. 1(B), upper panel], whereas after the addition of DFO, the height of peak $d$ increased, and a large new peak representing Fe bound to DFO appeared at 1 min [Fig. 1(B), lower panel]. Fe-peak a (at $23 \mathrm{~min}$ ) and Fe-peak d (at $39 \mathrm{~min}$ ) were therefore assigned to $\mathrm{Fe}_{\mathrm{C}}-\mathrm{hTf}$ and $\mathrm{Fe}_{\mathrm{N}}$-hTf, respectively. Urea-polyacrylamide gel electrophoresis (PAGE) ${ }^{31}$ ) was used to further ascertain the assignments of the two monoferric hTfs, and each of the peaks in the HPLC experiments was related to each of the bands in the urea-PAGE experiments: the peak at $23 \mathrm{~min}$ in the HPLC experiments was assigned to $\mathrm{Fe}_{\mathrm{C}}$-hTf, while the peak at $39 \mathrm{~min}$ was assigned to $\mathrm{Fe}_{\mathrm{N}}-$ hTf. $^{27)}$ 

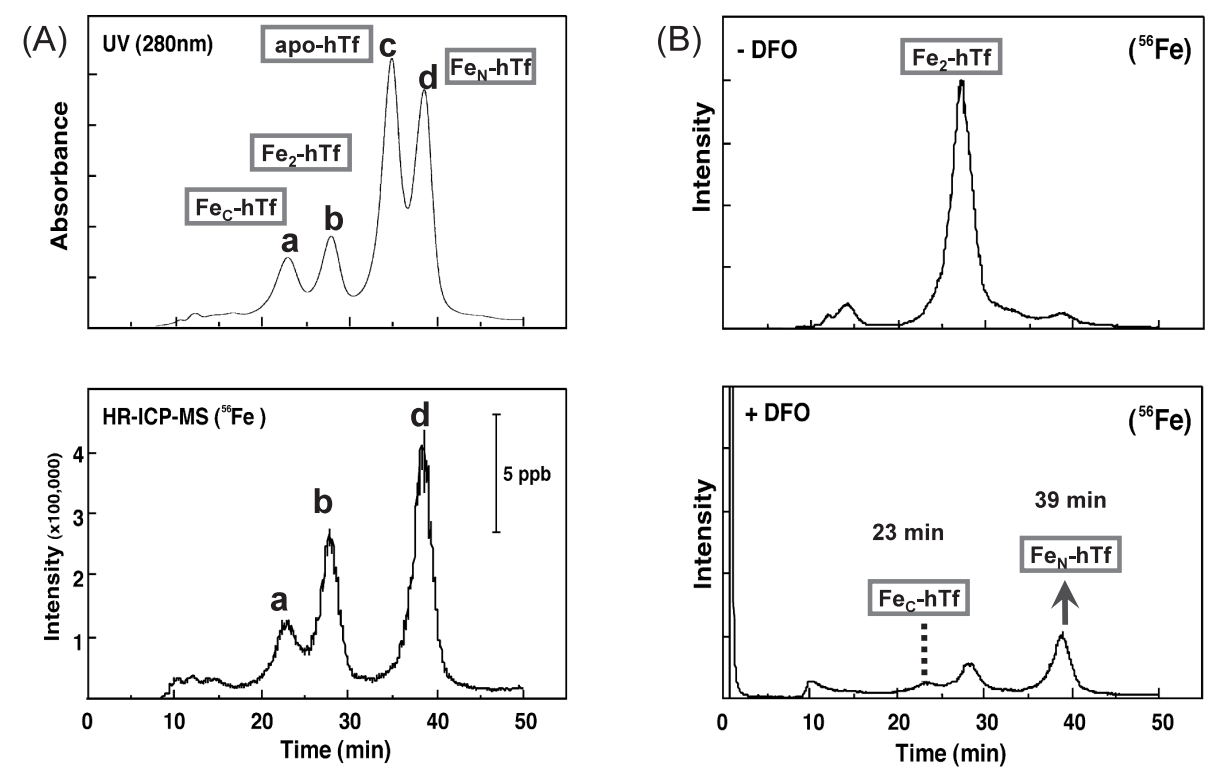

Fig. 1. Assignment of All Four Chemical Forms of Metals Bound to hTf (Modification of the Original Figure in Ref. 27)

(A) Typical HPLC/HR-ICP-MS chromatograms for apo-hTf partly saturated with $\mathrm{Fe}^{3+}(\mathrm{Fe}: \mathrm{hTf}=0.5: 1)$ in the presence of bicarbonate. (B) HPLC/HR-ICP-MS chromatograms ( ${ }^{56} \mathrm{Fe}$ level) for Fe-saturated hTf-solution before (top) and after (bottom) the addition of DFO.

\section{DETECTION OF METAL-hTf IN BLOOD FROM HEALTHY VOLUNTEERS WITH NO AI-SPIKES}

HR-ICP-MS is extremely sensitive and is the preferred method of analyzing biological samples, including serum. ${ }^{26,29,32-34)}$ The polyatomic ions that may be produced from protein samples in ICP-MS experiments are ${ }^{12} \mathrm{C}^{15} \mathrm{~N}^{+}(\mathrm{m} / \mathrm{z}$ 27.000), ${ }^{13} \mathrm{C}^{14} \mathrm{~N}^{+}(m / z, 27.006)$ and ${ }^{12} \mathrm{C}^{14} \mathrm{~N}^{1} \mathrm{H}^{+}$ $(\mathrm{m} / \mathrm{z}$ 27.011), and they interfere with the detection of ${ }^{27} \mathrm{Al}(\mathrm{m} / \mathrm{z}$ 26.982, natural abundance, $100 \%) .{ }^{35)}$ Moreover, polyatomic ion interference by ${ }^{40} \mathrm{Ar}^{16} \mathrm{O}^{+}$ with the detection of ${ }^{56} \mathrm{Fe}(\mathrm{m} / z \quad 55.935$; natural abundance, $91.7 \%$ ) is inevitable. ${ }^{36)}$ Although ${ }^{40} \mathrm{Ar}^{16} \mathrm{O}^{+}(m / z$ 55.957) can be reduced by orders of magnitude by using modern quadrupole-based instruments under cool plasma conditions or with a hexapole collision cell, HR-ICP-MS is still preferable, if available. Production of ${ }^{40} \mathrm{Ca}^{16} \mathrm{O}^{+}(\mathrm{m} / \mathrm{z}$ 55.958 ) may also interfere with the detection of ${ }^{56} \mathrm{Fe}$ in serum samples, since serum contains a Ca level of $100 \mathrm{mg} / \mathrm{l}$. Detection of ${ }^{32} \mathrm{~S}(\mathrm{~m} / z$ 31.972; natural abundance, $95.0 \%$ ) by HR-ICP-MS is a promising means of monitoring proteins, since proteins contain $\mathrm{S}$ atoms and the HR-ICP-MS instrument can separate ${ }^{32} \mathrm{~S}$ from ${ }^{16} \mathrm{O}_{2}^{+}(\mathrm{m} / \mathrm{z}$ 31.990). Thus, HPLC/HR-ICP-MS is a powerful method for simultaneously elucidating $\mathrm{Al}$ and $\mathrm{Fe}$ distribution patterns in serum.
To eliminate any $\mathrm{Al}$ or $\mathrm{Fe}$ adsorbed onto the column and lower the background levels of $\mathrm{Al}$ and $\mathrm{Fe}$, the column was cleaned with a sodium citrate solution prior to the start of each analysis. This step lowered the detection limit for $\mathrm{Al}$ to $0.1 \mu \mathrm{g} / \mathrm{l}(\mathrm{S} / \mathrm{N}=3)$, and the detection of limit for Fe to $0.02 \mu \mathrm{g} / \mathrm{l}$. In the absence of any $\mathrm{Al}$-spikes, the concentration of $\mathrm{Al}$ in the serum of healthy volunteers is about $3 \mu \mathrm{g} / \mathrm{l} .{ }^{37)}$

Figure 2 shows chromatograms depicting the ${ }^{32} \mathrm{~S},{ }^{56} \mathrm{Fe}$ and ${ }^{27} \mathrm{Al}$ levels in blood samples with no Al-spikes obtained from two healthy volunteers. It was possible to reproduce the chemical states of $\mathrm{Al}$ and $\mathrm{Fe}$ in fresh serum. ${ }^{29)}$ Therefore, as shown in Fig. 2, $\mathrm{Al}$ in the blood was present in the forms of $\mathrm{Al}_{\mathrm{N}}-\mathrm{hTf}$ and $\mathrm{Al}_{\mathrm{N}}, \mathrm{Fe}_{\mathrm{C}}-\mathrm{hTf}$. The height of the $\mathrm{Al}$ peak was almost as low as the detection limit level of $\mathrm{Al}$, because the $\mathrm{Al}$ level in the blood was very low $(3 \mu \mathrm{g} / \mathrm{l})$.

\section{EFFECTS OF C-LOBE SIALIC ACID RESIDUES OF hTf ON METAL BINDING}

Many types of plasma proteins in the blood are glycosylated with $\mathrm{N}$-linked oligosaccharides. hTf has carbohydrate chains in the C-lobe and has two potential glycosylation sites that are normally occupied by $N$-linked oligosaccharide chains, and $90 \%$ or more of the hTfs purified from the blood of healthy humans by affinity chromatogra- 

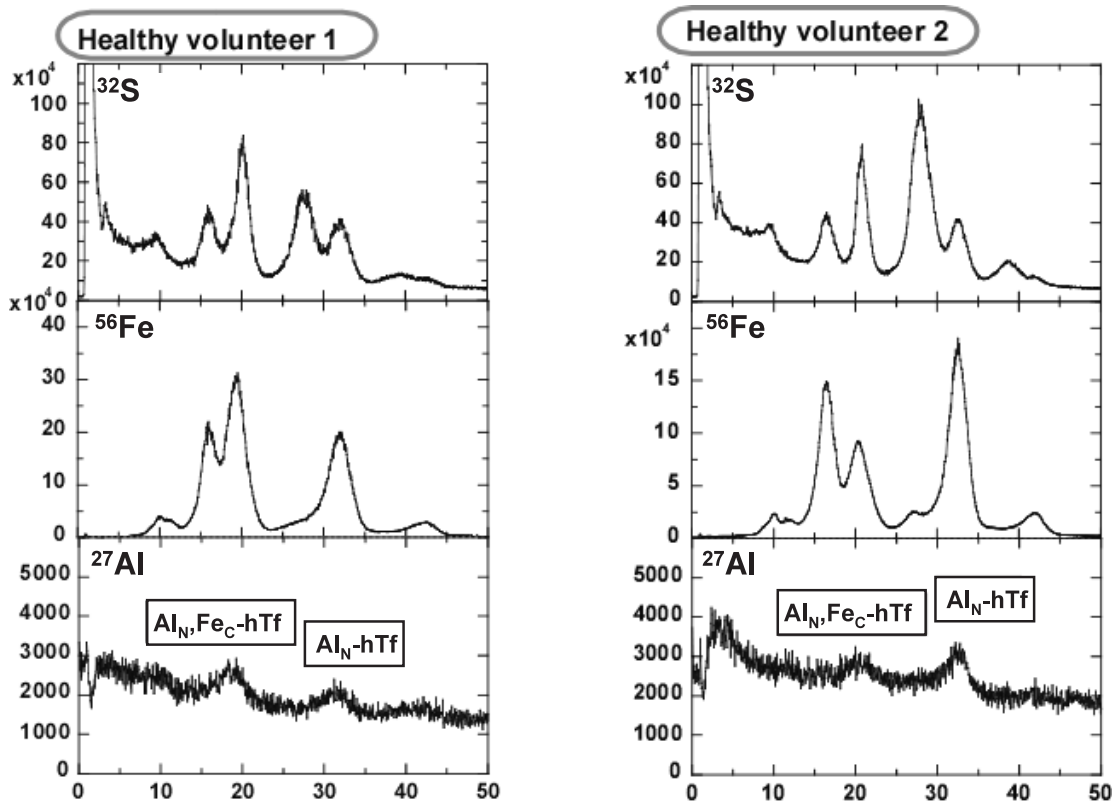

Fig. 2. HPLC/HR-ICP-MS $\left({ }^{32} \mathrm{~S},{ }^{56} \mathrm{Fe}\right.$ and $\left.{ }^{27} \mathrm{Al}\right)$ Chromatograms for Sera from Two Healthy Volunteers without Any Al-spikes (Modification of the Original Figures in Ref. 29)

phy with anti-Tf-Sepharose contain four sialic acid molecules. ${ }^{38)}$ On the other hand, the amounts of CDTs, which contain a smaller number of sialic acid residues, are reportedly elevated in several diseases. Carbohydrate-deficient glycoprotein (CDG) syndrome is a hereditary autosomal recessive disorder first reported by Jaeken et al. in $1984,{ }^{39)}$ and is characterized by severe nervous system symptoms, growth retardation, and hepatopathy during infancy. ${ }^{40)} \mathrm{A}$ decrease in tetrasialo-hTf followed by increases in disialo- and asialo-hTf isoforms has been observed in patients with CDG syndrome. ${ }^{41,42)}$

The increase of CDTs in the blood is observed in alcohol abuse or heavy drinking, and it disappears with abstinence. ${ }^{11,43-45)}$ hTfs containing smaller numbers of sialic acid residues in chronic alcohol abusers have been found to exhibit higher sialidase activity. ${ }^{46)}$ The free sialic acid level in blood is elevated by high alcohol consumption. ${ }^{47}$ )

The carbohydrate chain in the C-lobe site can differ both in degree of branching and number of sialic acid residues. hTfs exist as disialo, trisialo, tetrasialo, pentasialo, and asialo forms of hTf. ${ }^{48)}$ The existence of carboxylic acid residues in sialic acid molecules probably influences protein conformation and the principal function of hTf, thereby changing the binding affinity of hTf for metals. Moreover, if the presence of sialic acid residues in hTf affects metal binding to hTf, the metal-binding behavior of patients with increased CDT levels and of healthy persons may be different. To determine whether that is true, we compared the binding affinity of $\mathrm{Al}$ for native-hTf and for asialo-hTf. ${ }^{28)}$

To compare the binding affinity of $\mathrm{Fe}$ for native-hTf and asialo-hTf, we used sialidase (neuraminidase) to prepare asialo-hTf and supplemented native- and asialo-hTfs with an Fe-citrate mixture (Fe : citrate $:$ hTf ratio, $1: 1: 1$ ) in the presence of bicarbonate. Fe added in the form of Fe-citrate exhibited a preference for the $\mathrm{N}$-lobe site, and its binding affinity for native- and asialo-hTfs was similar, i.e., the heights of the Fe-peaks were comparable. Next, the binding affinity of $\mathrm{Al}$ for native-hTf and asialohTf was compared (Fig. 3), and the results showed that $\mathrm{Al}$ added as an Al-citrate complex had selectively bound to the N-lobe site and that its binding affinity for asialo-hTf was greater than for nativehTf.

Oxalate is present in serum, and its concentration enhanced in several diseases such as primary hyperoxaluria and nephrocalcalcinosis. ${ }^{49}$ ) We then examined the effect of oxalate on the binding of $\mathrm{Al}$ to hTf in the presence of bicarbonate (Fig. 4). Al was added in the form of Al-oxalate complex in a ratio of $1: 4$. The binding affinity of $\mathrm{Al}$ for the $\mathrm{N}$ lobe site of asialo-hTf increased further after the addition of the Al-oxalate, and the area of the metal 2 hTf peak also increased. There was a considerable difference between the Al-peaks for native-hTf and 

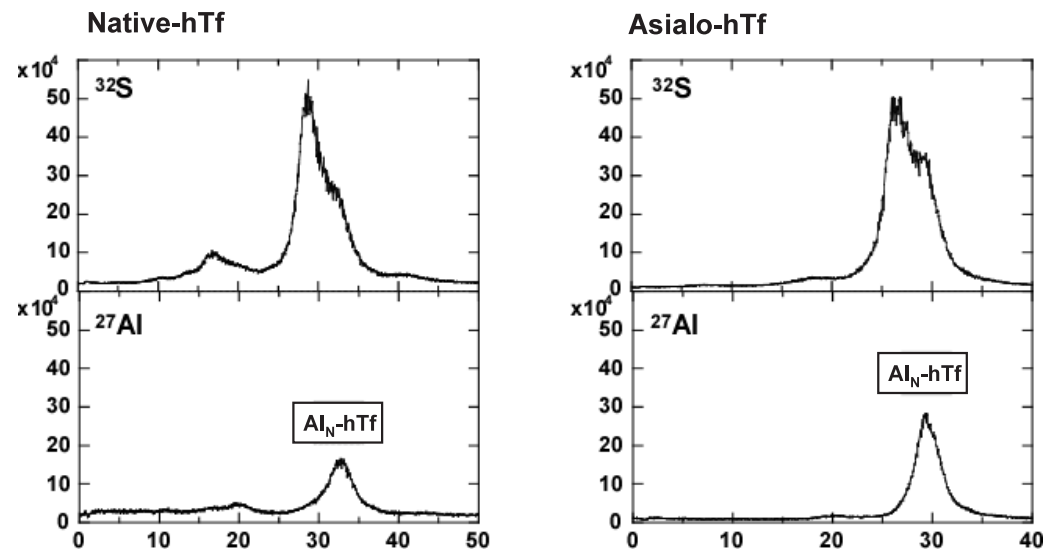

Fig. 3. HPLC/HR-ICP-MS $\left({ }^{32} \mathrm{~S}\right.$ and $\left.{ }^{27} \mathrm{Al}\right)$ Chromatograms for Native-apo-hTf Solution and Asialo-apo-hTf Solution plus Al-citrate $(\mathrm{Al}:$ citrate $=1: 1)$ in the Presence of Bicarbonate

The $\mathrm{Al}$ : hTf ratio was $1: 1$ (modification of the original figure in Ref. 28).


Fig. 4. HPLC/HR-ICP-MS $\left({ }^{32} \mathrm{~S}\right.$ and $\left.{ }^{27} \mathrm{Al}\right)$ Chromatograms for Native-apo-hTf Solution and Asialo-apo-hTf Solution plus Al-oxalate $(\mathrm{Al}:$ oxalate $=1: 4)$ in the Presence of Bicarbonate

The Al: hTf ratio was $1: 1$ (modification of the original figure in Ref. 28).

asialo-hTf. Surprisingly, in the absence of bicarbonate, Al-oxalate showed a preference for the C-lobe site in native-hTf and comparable affinity for both lobes of asialo-hTf. ${ }^{28)}$ Thus, the lack of sialic acid in the glycans and the presence of oxalate enhanced the binding affinity of $\mathrm{Al}$ for hTf.

In Fig. 4, the height of the metal 2 -asialo-hTf peak was larger than that of the metal $_{2}$-nativehTf peak. Since according to a previous report ${ }^{50)}$ metal $_{2}$-hTf is more easily transferred to the hTf receptor than monoferric-hTf or apo-hTf, $\mathrm{Al}_{2}$-hTf or Al,Fe-hTf may be easily incorporated into brain cells. Al may also easily pass through the bloodbrain barrier and cause toxicity. However, the affinity of hTf receptor 1 for Al bound to native-hTf was too weak to be detected in an in vitro experiment. ${ }^{51)}$ Furthermore, asialoglycoproteins bind to receptors in the liver, are taken up by the liver, and quickly disappear from the circulatory system. ${ }^{52,53)}$ Thus, despite several studies on this topic, the binding affinity of Al-native-hTf and Al-asialo-hTf for the Tf receptor and the actual degree of binding in the human body remain to be resolved.

The findings in this study suggest that the binding affinity of Al for hTf may be increased in patients whose blood contains CDTs. The oxalate concentration in the blood of healthy persons is approximately $2 \mu \mathrm{mol} / 1,{ }^{54)}$ but it is elevated in the serum of dialysis patients to $48.5 \mu \mathrm{mol} / \mathrm{l}$ before dialysis and $17.7 \mu \mathrm{mol} / 1$ after dialysis. ${ }^{55)}$ Under these conditions, $\mathrm{Al}$ toxicity may increase as a result of the increase in $\mathrm{Al}_{2}$-hTf or Al,Fe-hTf. Thus, the role of oxalate in Al-hTf binding and Al toxicity should be carefully considered in some diseases. 


\section{CONCLUSION}

This review has surveyed research on the binding affinity of $\mathrm{Al}$ for human $\mathrm{Tf}$ in the context of our recent studies.

The detection limit $(\mathrm{S} / \mathrm{N}=3)$ of ${ }^{27} \mathrm{Al}$ by HPLC/HR-ICP-MS was lowered to $0.1 \mu \mathrm{g} / \mathrm{l}$ by clean-up procedure.

$\mathrm{Al}$ in human serum with no in vitro $\mathrm{Al}$-spikes was detected as $\mathrm{Al}_{\mathrm{N}}-\mathrm{hTf}$ and metal 2 -hTf $\left(\mathrm{Al}_{\mathrm{N}}, \mathrm{Fe}_{\mathrm{C}^{-}}\right.$ hTf).

The absence of sialic acid residues in the carbohydrate chain of the C-lobe site of hTf and the presence of oxalate increased the binding affinity of $\mathrm{Al}$ for hTf, thereby possibly increasing Al toxicity.

Acknowledgements The research was supported partly by a Grant-in-Aid for Scientific Research from the Ministry of Education, Culture, Sports, Science and Technology of Japan.

\section{REFERENCES}

1) Sixty-seventh meeting of the Joint FAO/WHO Expert Committee on Food Additives (JECFA) (2007) Aluminium from all sources, including food additives (addendum). Safety evaluation of certain food additives and contaminants, WHO Food Additives Series, 58, 119-207.

2) Moraes, M. S. and Leite, S. R. (1994) Inhibition of bovine brain acetylcholinesterase by aluminum. Braz. J. Med. Biol. Res., 27, 2635-2638.

3) El-Demerdash, F. M. (2004) Antioxidant effect of vitamin $\mathrm{E}$ and selenium on lipid peroxidation, enzyme activities and biochemical parameters in rats exposed to aluminium. J. Trace Elem. Med. Biol., 18, 113-121.

4) Aramini, J. M., Saponja, J. A. and Vogel, H. J. (1996) Spectroscopic studies of the interaction of aluminum (III) with transferrins. Coord. Chem. Rev., 149, 193-229.

5) Bailey, S., Evans, R. W., Garratt, R. C., Gorinsky, B., Hasnain, S., Horsburgh, C., Jhoti, H., Lindley, P. F., Mydin, A., Sarra, R. and Watson, J. L. (1988) Molecular structure of serum transferrin at 3.3-A resolution. Biochemistry, 27, 5804-5812.

6) Anderson, B. F., Baker, H. M., Norris, G. E., Rumball, S. V. and Baker, E. N. (1990) Apolactoferrin structure demonstrates ligand-induced conformational change in transferrins. Nature, 344, 784787.
7) Baker, E. N., Anderson, B. F., Baker, H. M., Haridas, M., Jameson, G. B., Norris, G. E., Rumball, S. V. and Smith, C. A. (1991) Structure, function and flexibility of human lactoferrin. Int. J. Biol. Macromol., 13, 122-129.

8) MacGillivray, R. T., Mendez, E., Shewale, J. G., Sinha, S. K., Lineback-Zins, J. and Brew, K. (1983) The primary structure of human serum transferrin. The structures of seven cyanogen bromide fragments and the assembly of the complete structure. J. Biol. Chem., 258, 3543-3553.

9) Rohrer, J. S. and Avdalovic, N. (1996) Separation of human serum transferrin isoforms by highperformance pellicular anion-exchange chromatography. Protein Expr. Purif., 7, 39-44.

10) de Jong, G., van Dijk, J. P. and van Eijk, H. G. (1990) The biology of transferrin. Clin. Chim. Acta, 190, $1-46$.

11) Stibler, H. (1991) Carbohydrate-deficient transferrin in serum: a new marker of potentially harmful alcohol consumption reviewed. Clin. Chem., 37, 20292037.

12) Mihas, A. A. and Tavassoli, M. (1992) Laboratory markers of ethanol intake and abuse: a critical appraisal. Am. J. Med. Sci., 303, 415-428.

13) Rosman, A. S. and Lieber, C. S. (1994) Diagnostic utility of laboratory tests in alcoholic liver disease. Clin. Chem., 40, 1641-1651.

14) Inoue, T., Yamauchi, M. and Ohkawa, K. (1999) Structural studies on sugar chains of carbohydratedeficient transferrin from patients with alcoholic liver disease using lectin affinity electrophoresis. Electrophoresis, 20, 452-457.

15) Sillanaukee, P., Ponnio, M. and Seppa, K. (1999) Sialic acid: new potential marker of alcohol abuse. Alcohol Clin. Exp. Res., 23, 1039-1043.

16) Sonmez, H., Ozturk, Z. G., Ulutin, T., Domanic, N. and Kokoglu, E. (2000) Carbohydrate-deficient transferrin and sialidase levels in coronary heart disease. Thromb. Res., 99, 311-315.

17) Harris, W. R. and Sheldon, J. (1990) Equilibrium constants for the binding of aluminum to human serum transferrin. Inorg. Chem., 29, 119-124.

18) Martin, R. B., Savory, J., Brown, S., Bertholf, R. L. and Wills, M. R. (1987) Transferrin binding of $\mathrm{Al}^{+}$ and $\mathrm{Fe}^{+}$. Clin. Chem., 33, 405-407.

19) Martell, A. E., Hancock, R. D., Smith, R. M. and Motekaitis, R. J. (1996) Coordination of $\mathrm{Al}(\mathrm{III})$ in the environment and in biological systems. Coord. Chem. Rev., 149, 311-328.

20) Yokel, R. A., Allen, D. D. and Ackley, D. C. (1999) The distribution of aluminum into and out of the brain. J. Inorg. Biochem., 76, 127-132. 
21) Blancon Gonzalez, E., Perez Parajon, J., Garcia Alonso, J. I. and Sanz-Medel, A. (1989) Analytical approaches to the problem of protein binding of aluminium in blood serum. Journal of Analytical Atomic Spectrometry, 4, 175-179.

22) Garcia Alonso, J. I., Lopez Garcia, A., Sanz-Medel, A., Blancon Gonzalez, E., Ebdon, L. and Jones, P. (1989) Flow-injection and liquid chromatographic determination of aluminum based on its fluorimetric reaction with 8-hydroxyquinoline-5-sulphonic acid in a micellar medium. Anal. Chim. Acta, 225, 339350 .

23) Wrobel, K., Blancon Gonzalez, E., Wrobel, K. and Sanz-Medel, A. (1995) Aluminium and silicon speciation in human serum by lon-exchange highperformance liquid chromatography-electrothermal atomic absorption spectrometry and gel electrophoresis. Analyst, 120, 809-815.

24) Soldado Cabezuelo, A. B., Blanco González, E. and Sanz-Medel, A. (1997) Quantitative studies of aluminium binding species in human uremic serum by fast protein liquid chromatography coupled with electrothermal atomic absorption spectrometry. Analyst, 122, 573-577.

25) Soldado Cabezuelo, A. B., Montes Bayon, M., Blancon Gonzalez, E., Garcia Alonso, J. I. and Sanz-Medel, A. (1998) Speciation of basal aluminium in human serum by fast protein liquid chromatography with inductively coupled plasma mass spectrometric detection. Analyst, 123, 865-869.

26) Jakubowski, N., Moens, L. and Vanhaecke, F. (1998) Sector field mass spectrometers in ICP-MS. Spectrochim. Acta, Part B, 53, 1739-1763.

27) Nagaoka, M. H. and Maitani, T. (2000) Differed preferential iron-binding lobe in human transferrin depending on the presence of bicarbonate detected by HPLC/high-resolution inductively coupled plasma mass spectrometry. Biochim. Biophys. Acta, 1523, 182-188.

28) Nagaoka, M. H. and Maitani, T. (2001) Effects of sialic acid residues of transferrin on the binding with aluminum and iron studied by HPLC/highresolution ICP-MS. Biochim. Biophys. Acta, 1526, 175-182.

29) Nagaoka, M. H. and Maitani, T. (2000) Binding patterns of co-existing aluminium and iron to human serum transferrin studied by HPLC/high resolution ICP-MS. Analyst, 125, 1962-1965.

30) Folajtar, D. A. and Chasteen, N. D. (1982) Measurement of nonsynergistic anion binding to transferrin by EPR difference spectroscopy. J. Am. Chem. Soc., 104, 5775-5780.

31) Evans, R. W. and Williams, J. (1978) Studies of the binding of different iron donors to human serum transferrin and isolation of iron-binding fragments from the $\mathrm{N}$ - and C-terminal regions of the protein. Biochem. J., 173, 543-552.

32) Nagaoka, M. H., Yamazaki, T. and Maitani, T. (2002) Binding patterns of vanadium ions with different valence states to human serum transferrin studied by HPLC/high-resolution ICP-MS. Biochem. Biophys. Res. Commun., 296, 1207-1214.

33) Nagaoka, M. H., Akiyama, H. and Maitani, T. (2004) Binding patterns of vanadium to transferrin in healthy human serum studied with HPLC/high resolution ICP-MS, Analyst, 129, 51-54.

34) Nagaoka, M. H. and Maitani, T. (2005) Binding affinity of aluminium to human serum transferrin and effects of carbohydrate chain modification as studied by HPLC/high-resolution ICP-MSspeciation of aluminium in human serum-. J. Inorg. Biochem., 99, 1887-1894.

35) Yoshinaga, J., Shibata, Y., Uchiro, T., Morita, M., Kaneko, T., Iwanaga, M. and Ohtsuka, K. (1994) Determination of Aluminium in Serum by Inductively Coupled Plasma High Resolution Mass Spectrometry (ICP-HRMS), Biomed. Res. Trace Elem., 5, 259-260.

36) Giessmann, U. and Greb, U. (1994) High resolution ICP-MS a new concept for elemental mass spectrometry. Fresenius J. Anal. Chem., 350, 186-193.

37) Burgess, E., Muruve, D. and Audette, R. (1992) Aluminum absorption and excretion following sucralfate therapy in chronic renal insufficiency. Am. J. Med., 92, 471-475.

38) Yamashita, K., Ideo, H., Ohkura, T., Fukushima, K., Yuasa, I., Ohno, K. and Takeshita, K. (1993) Sugar chains of serum transferrin from patients with carbohydrate deficient glycoprotein syndrome. Evidence of asparagine- $\mathrm{N}$-linked oligosaccharide transfer deficiency. J. Biol. Chem., 268, 5783-5789.

39) Jaeken, J., van Eijck, H. G., van der Heul, C., Corbeal, L., Eeckels, R. and Eggermont, E. (1984) Sialic acid-deficient serum and cerebrospinal fluid transferrin in a newly recognized genetic syndrome. Clin. Chim. Acta, 144, 245-247.

40) Jaeken, J., Stibler, H. and Hagberg, B. (1991) The carbohydrate-deficient glycoprotein syndrome. A new inherited multisystemic disease with severe nervous system involvement. Acta Paediatrica Scandinavica Supplement, 375, 1-71.

41) Stibler, H. and Jaeken, J. (1990) Carbohydrate deficient serum transferrin in a new systemic hereditary syndrome. Arch. Dis. Child., 65, 107-111.

42) Yamashita, K., Ohkura, T., Ideo, H., Ohno, K. and Kanai, M. (1993) Electrospray ionization-mass 
spectrometric analysis of serum transferrin isoforms in patients with carbohydrate-deficient glycoprotein syndrome. J. Biochem., 114, 766-769.

43) Landberg, E., Pahlsson, P., Lundblad, A., Arnetorp, A. and Jeppsson, J. O. (1995) Carbohydrate composition of serum transferrin isoforms from patients with high alcohol consumption. Biochem. Biophys. Res. Commun., 210, 267-274.

44) Mihas, A. A. and Tavassoli, M. (1992) Laboratory markers of ethanol intake and abuse: a critical appraisal. Am. J. Med. Sci., 303, 415-428.

45) Rosman, A. S. and Lieber, C. S. (1994) Diagnostic utility of laboratory tests in alcoholic liver disease. Clin. Chem., 40, 1641-1651.

46) Xin, Y., Lasker, J. M. and Lieber, C. S. (1995) Serum carbohydrate-deficient transferrin: mechanism of increase after chronic alcohol intake. Hepatology, 22, 1462-1468.

47) Sillanaukee, P., Ponnio, M. and Seppa, K. (1999) Sialic acid: new potential marker of alcohol abuse. Alcohol Clin. Exp. Res., 23, 1039-1043.

48) Yang, L., Tang, Q., Harrata, A. K. and Lee, C. S. (1996) Capillary isoelectric focusing-electrospray ionization mass spectrometry for transferrin glycoforms analysis. Anal. Biochem., 243, 140-149.

49) Bastani, B., Mistry, B. M., Nahass, G. T., Joh, J., Dundoo, G. and Solomon, H. (1999) Oxalate kinetics and reversal of the complications after orthotopic liver transplantation in a patient with primary hyperoxalosis type 1 awaiting renal transplantation. Am.
J. Nephrol., 19, 64-69.

50) Young, S. P., Bomford, A. and Williams, R. (1984) The effect of the iron saturation of transferrin on its binding and uptake by rabbit reticulocytes. Biochem. J., 219, 505-510.

51) Hemadi, M., Miquel, G., Kahn, P. H. and El Hage Chahine, J. M. (2003) Aluminum exchange between citrate and human serum transferrin and interaction with transferrin receptor 1 . Biochemistry, 42, 31203130.

52) Pardridge, W. M., Van Herle, A. J., Naruse, R. T., Fierer, G. and Costin, A. (1983) In vivo quantification of receptor-mediated uptake of asialoglycoproteins by rat liver. J. Biol. Chem., 258, 990-994.

53) Morell, A. G., Irvine, R. A., Sternlieb, I., Scheinberg, I. H. and Ashwell, G. (1968) Physical and chemical studies on ceruloplasmin. V. Metabolic studies on sialic acid-free ceruloplasmin in vivo. J. Biol. Chem., 243, 155-159.

54) Ogawa, Y., Hokama, S., Yonou, H., Oshiro, Y., Machida, N., Gakiya, M., Chinen, Y., Jahana, M., Yajima, A., Uchida, A., Morozumi, M. and Sugaya, K. (2004) In serum calcium oxalate supersaturation a potential risk factor for tissue deposition of crystals in dyalysis patients. Kidney and Metabolic Bone Diseases, 17, 299-304.

55) Gaulier, J. M., Cochat, P., Lardet, G. and Vallon, J. J. (1997) Serum oxalate microassay using chemiluminescence detection. Kidney Int., 52, 1700-1703. 